\title{
Genetic Diversity of Pseudomonas savastanoi pv. savastanoi in California and Characterization of Epidemiological Factors for Olive Knot Development
}

\author{
K. A. Nguyen, H. Förster, and J. E. Adaskaveg, ${ }^{\dagger}$ Department of Microbiology and Plant Pathology, University of California, Riv- \\ erside 92521
}

\begin{abstract}
Olive knot, caused by Pseudomonas savastanoi pv. savastanoi, is a limiting disease in the production of table and oil olives in California. The genetic variability among 152 strains from major production areas of California was determined using BOX, ERIC, and REP primers in repetitive element sequence-based polymerase chain reaction. Overall genetic variability was low, and strains shared at least $82 \%$ similarity. Phenetic analyses identified several genotypes but most strains belonged to one of two major groups. Three copper-resistant strains had two fingerprints that were distinct from any of the sensitive strains, indicating that they may have been introduced from other production areas or hosts. In inoculations, two copper-resistant

strains were mostly equally as virulent as two copper-sensitive strains. Inoculum was exuded at high levels ( $>10^{8} \mathrm{CFU} / \mathrm{g}$ of knot tissue) within $10 \mathrm{~min}$ from hydrated olive knots, and concentrations were 2- to 3-log higher than the minimum needed to induce knot formation. Arbequina olive was significantly more susceptible to infection and developed a higher incidence of knots on leaf scar and lateral wounds (59.7 to 80.6\% incidence) than Manzanillo (47.4 to $68.2 \%$ incidence). In wound-healing studies, both types of wounds were less susceptible to infection $\geq 10$ days after injury, indicating a critical period for infection and application of bactericides during favorable environments.
\end{abstract}

Olive knot, caused by the phytobacterium Pseudomonas savastanoi pv. savastanoi, has been present in California for over a century. It was likely introduced into the state on olive (Olea europaea L.) plants imported from the Mediterranean region during the late 1800 s, when commercial plantings were established (Bioletti 1898). P. savastanoi pv. savastanoi is a pathogen infecting wounds that are created mechanically (Young 2004) or by natural causes such as leaf drop or cold injury (Ogawa and English 1991). Wetness from rain contacting olive knots, the primary inoculum source, promotes the release and dissemination of the bacterium to susceptible wounds (Horne et al. 1912). Infections lead to the development of new knots or galls mostly on twigs, trunks, and branches, resulting in reduced tree vigor and yield (Schroth et al. 1973; Wilson 1935). Over the last 10 years, olive oil production has been increasing in California with the implementation of novel cultural techniques such as high-density planting systems where mechanical pruning and harvesting methods are used (Tous et al. 2010; Vossen 2007). These new methods allow growers to reduce labor costs and remain profitable. However, they also increase the risk of spreading olive knot because pruning and harvesting equipment cause a greater number of susceptible injuries to olive than traditional techniques (Quesada et al. 2010). Furthermore, equipment becomes contaminated with the bacterium from contact with diseased trees and can effectively disseminate the pathogen to healthy trees (Nguyen et al. 2017; Tous et al. 2010)

Olive knot is widespread in oil and table olive production areas in California, especially those with higher rainfall, but no information is available on the genetic diversity in $P$. savastanoi pv. savastanoi populations among orchards and growing areas. Repetitive element sequence-based polymerase chain reaction (rep-PCR), random amplification of polymorphic DNA, multilocus sequencing, and amplified fragment length polymorphisms (AFLP) have been used to fingerprint bacterial strains and study the population structure of the pathogen in other areas (Krid et al. 2009; Moretti et al. 2017; Scortichini et al. 2004; Sisto et al. 2007; Tsuji et al. 2017). For example,

${ }^{\dagger}$ Corresponding author: J. E. Adaskaveg; E-mail: jim.adaskaveg@ucr.edu

Funding: This work was supported with funding from the California Olive Committee and the Olive Oil Council of California.

Accepted for publication 5 March 2018.

() 2018 The American Phytopathological Society random amplified polymorphic DNA analyses identified three main clusters among strains from Tunisia that correlated with locations within the country, and only one of the clusters also comprised strains from other European countries and from the United States (Krid et al. 2009). In another study, rep-PCR analyses of strains from several Mediterranean countries detected numerous haplotypes, and clustering of strains was based on their geographic origin (Moretti et al. 2017). Similarly, strains of $P$. savastanoi pv. savastanoi from various hosts in several European countries grouped together based on their geographic origin using AFLP banding patterns (Sisto et al. 2007). Using rep-PCR, a high degree of polymorphism with 20 haplotypes was detected among 360 strains from olive in Italy but no distinct genetic clusters were identified (Scortichini et al. 2004), and a geographic grouping was not attempted. Knowledge about the population structure of a pathogen may provide insight into its spread and possible adaptation to host cultivars or certain ecological niches with specific microclimates in a geographical region. Such information may also offer clues on the genetic relatedness and origin of copper-resistant strains of $P$. savastanoi pv. savastanoi in California that were recently identified (Nguyen et al. 2018).

Important management strategies for olive knot are the use of clean nursery stock, prevention of injuries to trees, pruning and removal of infected plant material, sanitation of field equipment, and protective applications with copper bactericides or one of the few copper alternatives currently available (Nguyen et al. 2017, 2018). To provide the most effective disease control, chemical strategies should be properly timed in respect to environmental conditions, injury and infection events, presence of sufficient inoculum, as well as time of host susceptibility. The epidemiology of olive knot has been well studied (Ramos et al. 2012) but little is known in relation to current California olive production practices that utilize only a few cultivars, mostly of Spanish origin (Vossen 2007). This includes understanding the extent of bacterial inoculum being exuded from knots, inoculum concentrations necessary to induce disease, and the period of wound susceptibility to infection.

The objectives of this study were to (i) determine the genetic diversity of $P$. savastanoi pv. savastanoi in major olive production areas of California and elucidate the possible origin of copper-resistant strains, (ii) quantify natural inoculum concentrations exuding from hydrated olive knots and determine inoculum concentrations necessary to induce disease on major olive cultivars grown in California, (iii) compare the virulence of copper-sensitive and -resistant strains of $P$. savastanoi pv. savastanoi, and (iv) determine the duration of susceptibility of lateral twig and leaf scar wounds to infection. 


\section{Materials and Methods}

Culturing of $\boldsymbol{P}$. savastanoi pv. savastanoi strains and of olive plants in the field. In total, 147 strains of $P$. savastanoi pv. savastanoi that were previously isolated from olive knots collected in commercial oil and table olive orchards in major production areas of California (Butte, Colusa, Glenn, Tehama, Tulare, and Yuba Counties) (Nguyen et al. 2018) and 5 strains from knots collected at the United States Department of Agriculture National Clonal Germplasm Repository for olive at the University of California (UC) Wolfskill Experimental Orchards, Yolo County, were used in this study (Table 1). All 152 strains were initially selected based on colony morphology and blue fluorescence under UV light (365-nm wavelength) on the semiselective medium PVF-1 (Surico and Lavermicocca 1989). Molecular identification was performed using primers targeting the iaaL gene (Penyalver et al. 2000) and the pathovar-specific primers PsvF and PsvR (Tegli et al. 2010). Cultures were maintained in 15\% glycerol at $-80^{\circ} \mathrm{C}$. Strains were grown on King's medium B (KMB) (King et al. 1954) for $48 \mathrm{~h}$ at 22 to $25^{\circ} \mathrm{C}$ before use. Field trials were conducted using Arbequina and Manzanillo olive trees (Agromillora California, Gridley, CA). Trees were planted at the UC Davis and Riverside field stations similar to high-density commercial olive orchards using a trellis system (Vossen 2007). Tree spacing within a row was approximately $2 \mathrm{~m}$, and the distance between rows was approximately $5 \mathrm{~m}$. Trees were irrigated and fertilized using standard commercial practices. For greenhouse trials, Arbequina olive trees were grown at 20 to $30^{\circ} \mathrm{C}$ in $7.57-$ liter pots in sterilized soil.

Genetic fingerprinting of $\boldsymbol{P}$. savastanoi pv. savastanoi strains. rep-PCR was utilized to determine the genetic variability among 152 P. savastanoi pv. savastanoi strains using BOX, ERIC, and REP primers (Rademaker and de Bruijn 1997). PCR contained the following in a total volume of $25 \mu \mathrm{l}: 2.5 \mu \mathrm{l}$ of $10 \times$ reaction buffer (Apex; Genesee Scientific, San Diego, CA), 1 U of Taq-DNA polymerase (Apex; Genesee Scientific), $500 \mathrm{nM}$ primers BOXA1R, ERIC1R and ERIC2, or REPIR1 and REP2I, $0.25 \mu$ l of bovine serum albumin $(10 \mu \mathrm{g} / \mathrm{ml}$; Sigma Aldrich, St. Louis), and $100 \mu \mathrm{M}$ each dNTP (Genesee Scientific). For each strain, $1 \mu l$ of an aqueous bacterial suspension (adjusted to $70 \%$ transmittance at an optical density at $\left.600 \mathrm{~nm}\left[\mathrm{OD}_{600}\right]\right)$ from a 24-h-old culture was used as DNA template per reaction, and amplifications were done in a PTC-200 thermal cycler (MJ Research, Inc., Waltham, MA). Amplification conditions were as described previously (Rademaker and de Bruijn 1997) but the extension step was reduced to $2 \mathrm{~min}$, and 35 cycles were performed. Amplification products were separated in $1.5 \%$ agarose (containing ethidium bromide at $1 \mu \mathrm{g} / \mathrm{ml}$ ) in $0.5 \times$ Trisborate-EDTA buffer for $2 \mathrm{~h}$ at $140 \mathrm{~V}$. A 100-bp ladder (Bioland Scientific, Paramount, CA) was used as DNA size marker. Amplifications were repeated at least once for all strains and primers, and only bands that were consistently amplified were scored.

Inoculum production from wetted olive knots, virulence of copper-sensitive and -resistant strains, and susceptibility of two olive cultivars. Approximately 2-year-old Arbequina olive twigs were inoculated in the field with $P$. savastanoi pv. savastanoi strain $\mathrm{O} 26$, as described below. After 6 months, the amount of inoculum released from knots was determined following selected time periods of soaking in water. For this, knots of similar size (i.e., approximately $1 \mathrm{~cm}$ in diameter) and with living green tissue were excised by cutting twigs at opposite sides of knots and weighed. Knots were surface disinfected for $1 \mathrm{~min}$ in a 1:10 dilution of household bleach and rinsed three times with sterile distilled water, and each knot was placed into a 50-ml plastic tube containing $5 \mathrm{ml}$ of sterile water. Tubes were kept at $25^{\circ} \mathrm{C}$ on a shaker (model G24; New Brunswick Scientific Co., Inc., Edison, NJ) at $100 \mathrm{rpm}$, and $10-\mu 1$ samples were taken almost immediately (within $10 \mathrm{~min}$ ) and after 4, 8, and $24 \mathrm{~h}$. Samples were diluted 1:10,000 with sterile water before plating onto $10-\mathrm{cm} \mathrm{KMB}$ media plates with a spiral plater (Autoplate 4000; Spiral Biotech, Inc., Norwood, MA). Colonies that emitted a blue fluorescence under UV light $(365 \mathrm{~nm})$ were enumerated after 3 days of growth at $25^{\circ} \mathrm{C}$, and $\mathrm{CFU}$ were calculated per gram of knot weight. A subsample of 20 colonies was verified as $P$. savastanoi pv. savastanoi in PCR with primers targeting the $i a a L$ gene (Penyalver et al. 2000). In each of the two studies, 10 replicated knots were evaluated for each wetness duration. Concentrations of bacteria recovered were expressed as $\log _{10} \mathrm{CFU} / \mathrm{g}$ of knot tissue.

To determine the effect of inoculum concentration on knot formation and to compare the virulence of copper-sensitive and -resistant strains, lateral and leaf scar wounds were made to 2-year-old Arbequina branches $5 \mathrm{~mm}$ in diameter. Lateral wounds were made by removing a piece of bark ( 5 by $10 \mathrm{~mm}$ ) with a sterile scalpel so that cambial tissue was exposed. Leaf scar wounds were created by removing leaves by hand. Inoculum was prepared for two coppersensitive strains (O14 and O26; no growth with metallic copper at $>20 \mu \mathrm{g} / \mathrm{ml}$ ) and two copper-resistant strains (O113 and O145; growth with metallic copper at $\geq 50 \mu \mathrm{g} / \mathrm{ml}$ ) of $P$. savastanoi $\mathrm{pv}$. savastanoi that were previously characterized (Nguyen et al. 2018). Aqueous inoculum suspensions (approximately $10^{8} \mathrm{CFU} / \mathrm{ml}$, as determined by transmittance of $70 \%$ at $\mathrm{OD}_{600}$ ) of each strain were serially diluted to obtain a range of concentrations from $10^{5}$ to $10^{8} \mathrm{CFU} / \mathrm{ml}$. Inoculum was applied to wounds by spraying to runoff using a spray bottle or by placing a $10-\mu l$ droplet on each wound using a pipette. Two field studies were performed using the spray inoculation method with strains O26 and O113 in 2014 and 2015, and two greenhouse studies were done using droplet inoculations with strains O14, O26, O113, and O145 in 2015 and 2017. For each study, a twig represented an experimental replicate with five lateral and five leaf scar wounds, and six to eight replicates were done for each inoculum concentration, strain, and wound type. Treatments were arranged in a randomized complete block design (RCBD).

To compare susceptibility of two major commercial olive cultivars, lateral and leaf scar wounds on Arbequina and Manzanillo olive

Table 1. Origin of Pseudomonas savastanoi pv. savastanoi strains from California used in this study and their fingerprint patterns based on repetitive element sequence-based polymerase chain reaction (rep-PCR) ${ }^{\mathrm{a}}$

\begin{tabular}{|c|c|c|c|}
\hline $\begin{array}{l}\text { Olive } \\
\text { cultivar }\end{array}$ & $\begin{array}{l}\text { County- } \\
\text { orchard }\end{array}$ & $\begin{array}{c}\text { Fingerprint patterns/number of } \\
\text { strains }^{\text {b }}\end{array}$ & $\begin{array}{c}\text { Total } \\
\text { number of } \\
\text { strains }\end{array}$ \\
\hline Koroneiki & Glenn-1 & $\mathrm{A} / 13$ & 13 \\
\hline Manzanillo & Glenn-2 & $\mathrm{A} / 6, \mathrm{~B} / 1$ & 7 \\
\hline Arbequina & Yuba-1 & $\mathrm{A} / 3, \mathrm{~B} / 2$ & 5 \\
\hline Arbosana & Yuba-2 & $\mathrm{A} / 4, \mathrm{C} / 1$ & 5 \\
\hline Manzanillo & Glenn-3 & $\mathrm{A} / 3, \mathrm{~B} / 2, \mathrm{D} / 1$ & 6 \\
\hline Manzanillo & Glenn-4 & $\mathrm{A} / 6$ & 6 \\
\hline Manzanillo & Glenn-5 & $\mathrm{B} / 10$ & 10 \\
\hline Arbequina & Butte-1 & $\mathrm{A} / 8$ & 8 \\
\hline Unknown & Tulare-1 & $\mathrm{B} / 6$ & 6 \\
\hline Manzanillo & Tehama-1 & $\mathrm{A} / 3, \mathrm{~B} / 2$ & 5 \\
\hline Manzanillo & Glenn-6 & $\mathrm{A} / 2$ & 2 \\
\hline Sevillano & Tehama-2 & $\mathrm{A} / 1, \mathrm{E} / 1$ & 2 \\
\hline Arbequina & Glenn-7 & $\mathrm{A} / 4, \mathrm{~B} / 3$ & 7 \\
\hline Manzanillo & Glenn-8 & $\mathrm{A} / 4$ & 4 \\
\hline Manzanillo & Glenn-9 & $\mathrm{A} / 1, \mathrm{~B} / 3, \mathrm{~F} / 2$ & 6 \\
\hline Manzanillo & Tehama-3 & $\mathrm{A} / 3, \mathrm{~B} / 2$ & 5 \\
\hline Arbequina & Tehama-4 & $\mathrm{A} / 3, \mathrm{~B} / 1, \mathrm{D} / 1$ & 5 \\
\hline Sevillano & Tehama-5 & $\mathrm{A} / 2, \mathrm{~B} / 2, \mathrm{G} / 1$ & 5 \\
\hline Manzanillo & Glenn-10 & $\mathrm{B} / 4, \mathrm{H} / 1$ & 5 \\
\hline Arbosana & Yuba-3 & $\mathrm{A} / 4$ & 4 \\
\hline Arbequina & Yuba-4 & $\mathrm{A} / 2$ & 2 \\
\hline Arbequina & Yuba-5 & $\mathrm{A} / 4, \mathrm{I} / 1$ & 5 \\
\hline Arbequina & Yuba-6 & $\mathrm{A} / 4$ & 4 \\
\hline Manzanillo & Glenn-11 & $\mathrm{A} / 5, \mathrm{~B} / 6$ & 11 \\
\hline Sevillano & Glenn-12 & $\mathrm{A} / 1, \mathrm{~B} / 6, \mathrm{H} / 1, \mathrm{~J} / 1$ & 9 \\
\hline Manzanillo & Yolo-1 & $\mathrm{B} / 3$ & 3 \\
\hline Sevillano & Yolo-1 & $\mathrm{B} / 1$ & 1 \\
\hline Arbosana & Yolo-1 & $\mathrm{B} / 1$ & 1 \\
\hline Total & $\ldots$ & $\begin{array}{l}\mathrm{A} / 86, \mathrm{~B} / 55, \mathrm{C} / 1, \mathrm{D} / 2, \mathrm{E} / 1, \mathrm{~F} / 2, \mathrm{G} / 1 \\
\mathrm{H} / 2, \mathrm{I} / 1, \mathrm{~J} / 1\end{array}$ & 152 \\
\hline
\end{tabular}

a Ten fingerprint patterns (A to $\mathrm{J}$ ) are based on rep-PCR using BOX, ERIC, and REP primers.

${ }^{\mathrm{b}}$ In each location the fingerprint group(s) and the number of isolates found within each group are indicated. 
twigs were inoculated with serial dilutions of bacterial suspensions from $10^{5}$ to $10^{8} \mathrm{CFU} / \mathrm{ml}$, as described above, using strain $\mathrm{O} 26$. Two repeated studies were done (September 2014 and October 2014) at UC Davis, and disease was evaluated after approximately 10 months. In each of the two studies, each twig represented an experimental replicate with five lateral and five leaf scar wounds, and six to eight replicates were done for each inoculum concentration, cultivar, and wound type. Treatments were arranged in a RCBD.

Duration of susceptibility of lateral twig and leaf scar wounds to infection by $\boldsymbol{P}$. savastanoi pv. savastanoi. Manzanillo olive twigs were injured to create lateral and leaf scar wounds, as described above. Wounds were inoculated immediately or after 10, 20, or 30 days. Wounds were spray inoculated with $P$. savastanoi pv. savastanoi strain $\mathrm{O} 26\left(10^{7} \mathrm{CFU} / \mathrm{ml}\right)$ until runoff. For each wound age, five twig replicates were used, each with five lateral and five leaf scar wounds, and each set of timings was on a separate tree. The experiment was done twice in October 2012 at UC Davis, and evaluations were made after 8 months. The California Irrigation Management Information System was used to monitor average precipitation, average temperature, and average humidity at UC Davis for a 30-day period after wounding.

Data analysis. Fingerprint patterns of rep-PCR were scored based on the presence (score $=1$ ) or absence (score $=0$ ) of a band for each strain for the three primer sets used and were entered into a combined binary data matrix. Cluster analysis was done using the NTSYSpc software (ver.2.21q) (Rohlf 2009). First, similarities in pairwise comparisons of fingerprint patterns were generated using Dice's coefficient (SIMQUAL). Clustering was performed using the unweighted pairgroup method with arithmetic means (UPGMA) in SAHN. A dendrogram was generated (TREE). To determine how well the dendrogram represented the original similarity matrix, a matrix of cophenetic values was created $(\mathrm{COPH})$ and compared for goodness of fit with the original matrix (MXCOMP, set to five permutations).

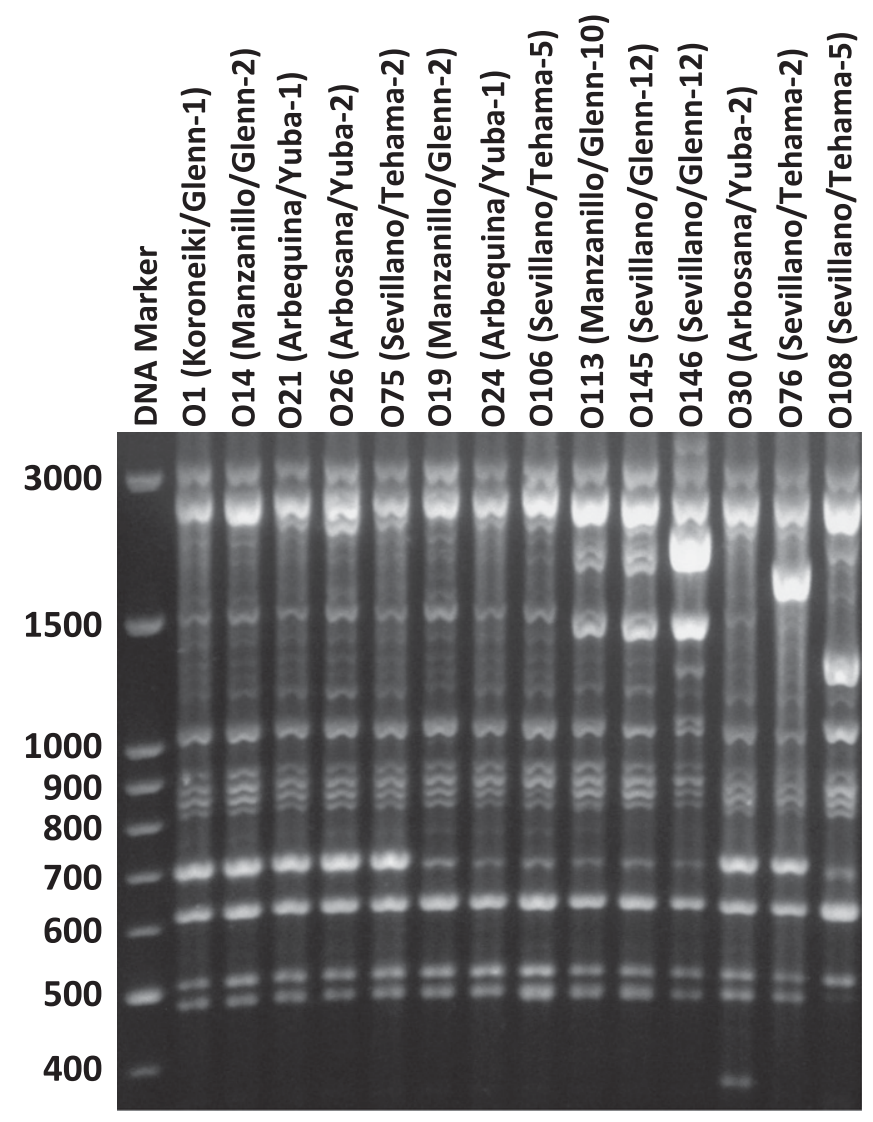

Fig. 1. Agarose gel electrophoresis of polymerase chain reaction amplification products of 14 strains of Pseudomonas savastanoi pv. savastanoi using primers REP1RI and REP2-I.
For additional statistical analyses, data for inoculum production were $\log _{10}$-transformed, whereas percent disease incidence data for the inoculation studies were arcsin-transformed. Variances for repeated studies were evaluated using Bartlett's test of homogeneity. Because all data sets were homogeneous, data for repeated studies were combined. Mean values and standard errors for inoculum production and percent disease incidence were calculated for each inoculum concentration, strain (i.e., copper-sensitive and -resistant), and cultivar (i.e., Arbequina and Manzanillo) evaluated. For spray inoculation studies, a two-way analysis of variance (ANOVA) was done for the variables bacterial strain or cultivar, concentration of inoculum, and the interaction of these variables. For droplet inoculations, general linear model (GLM) procedures were used for the variables bacterial strain, concentration of inoculum, and the interaction of these variables. Because percent incidence of disease between the two copper-sensitive strains or the two copper-resistant strains was not significantly different at each inoculum concentration, data were combined. A one-way ANOVA was used to test the effects of inoculation time after wounding on the incidence of disease for both lateral and leaf scar wounds. Homogeneity of variances, ANOVA, GLM, and least significant difference mean separation procedures were done using a statistical software package (SAS ver. 9.4; SAS Institute, Cary, NC).

\section{Results}

Genetic fingerprinting of $\boldsymbol{P}$. savastanoi pv. savastanoi strains. The REP primer set identified the majority of polymorphisms among the 152 strains evaluated and was the most discriminatory among the rep-PCR primers utilized. Overall genetic variability among strains, however, was low and most belonged to one of two groups (A and B) based on the presence of a distinct and reproducible DNA fragment

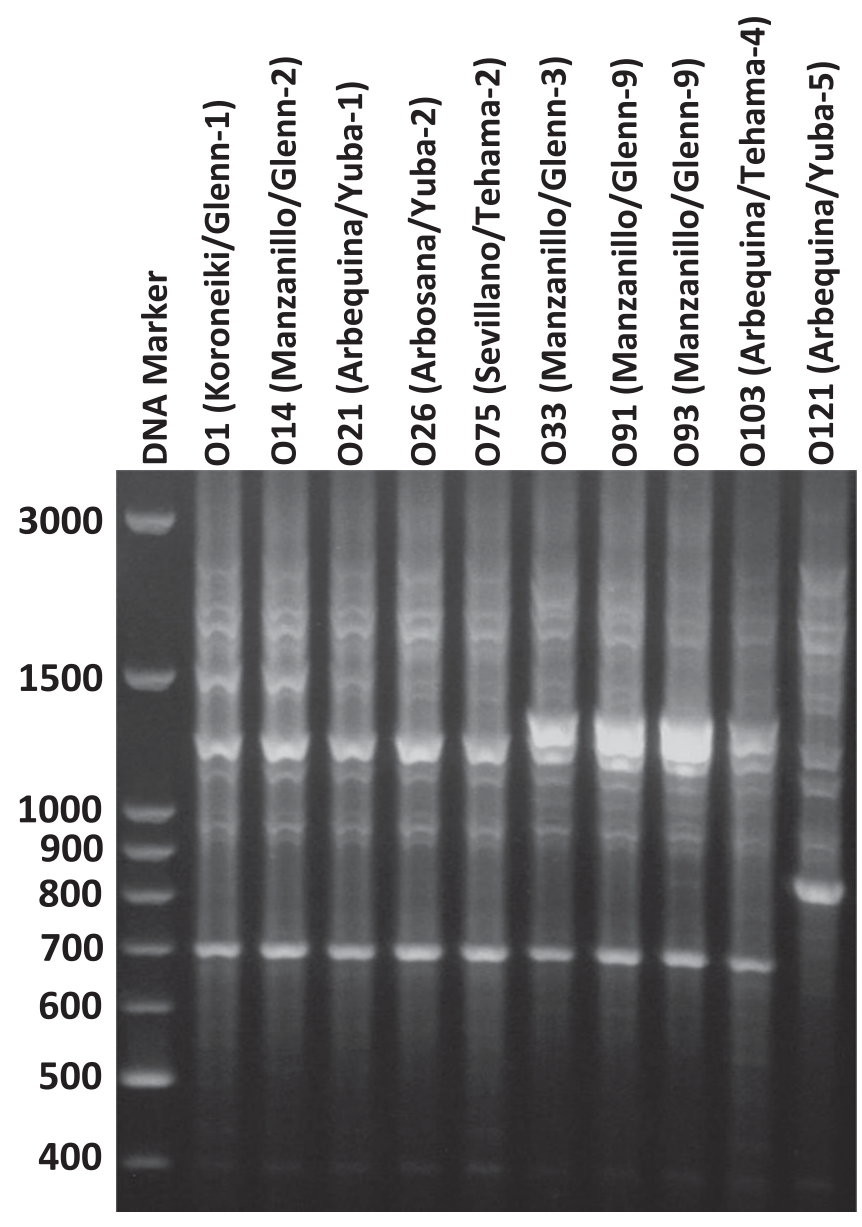

Fig. 2. Agarose gel electrophoresis of polymerase chain reaction amplification products of 10 strains of Pseudomonas savastanoi pv. savastanoi using primer BOXA1R. 
approximately $700 \mathrm{bp}$ in length (Table 1, Fig. 1). Two of the three copper-resistant strains (O113 and O145) shared identical fingerprints that were distinct from the third strain (O146), and the latter three strains displayed unique bands not observed in any of the other strains. Several additional strains had unique fingerprints. Using the ERIC primer set, banding patterns were identical for all strains (data not shown). For the BOX primer, most strains were identical except for four strains (i.e., O33, O91, O93, and O103) that had a band that was absent in the other strains, and another strain (O121) amplified a unique band not shared with any of the remaining strains (Fig. 2).

The phenetic analysis of 15 polymorphic bands identified in repPCR resulted in similarity and cophenetic matrices with a cophenetic correlation value of 0.954 . In the UPGMA dendrogram, several clusters of $P$. savastanoi pv. savastanoi strains group closely together, and no distinct lineages are evident (Fig. 3). The majority of strains belong to two groups, A and B. Group A contains strains from all five olive cultivars sampled in Butte, Glenn, Tehama, and Yuba Counties whereas, in group B, strains from four cultivars in Glenn, Tehama, Tulare, Yolo, and Yuba Counties are found (Table 1). Overall, Glenn County had the highest diversity in $P$. savastanoi pv. savastanoi strains, with six fingerprint patterns, followed by Tehama County, with five patterns, and Yuba County, with four patterns. In some of the orchards in these counties, more than one genotype was detected (e.g., Glenn-12, Tehama-2, and Yuba-1). Strains from Butte, Tulare, and Yolo Counties each had a single fingerprint pattern but only one orchard was sampled for each of these counties (Table 1). A strain from Sevillano olive in Tehama County was the most distinct, with the lowest similarity coefficient (i.e., 0.82) in comparison with the most dissimilar strains. Two copper-resistant strains from Glenn County were identical and grouped closely with the third strain (Fig. 3). These copper-resistant strains did not cluster with any of the other strains, including those from the same orchard (i.e., locations 10 and 12).

Inoculum production from wetted olive knots, virulence of copper-sensitive and -resistant strains, and susceptibility of two olive cultivars. Excised knots that were soaked in water exuded large quantities of bacteria almost immediately (within $10 \mathrm{~min}$ ), and the bacterial concentration in the water suspension increased from $10^{8}$ to $\geq 10^{9} \mathrm{CFU} / \mathrm{g}$ of knot tissue over a 24 -h period. All 20 of the subsampled colonies recovered from knots on KMB were fluorescent under UV light and were confirmed as P. savastanoi pv. savastanoi based on amplification of the iaaL gene.

The amount of inoculum to induce knot development was subsequently evaluated. The overall ANOVA models were highly significant $(P<0.0001)$ for both leaf scars and lateral wounds that were spray inoculated with two $P$. savastanoi pv. savastanoi strains in the field. For copper-sensitive and -resistant strains and for both types of wounds, incidence of knot formation increased significantly $(P<0.0001)$ for inoculum concentrations from $10^{5}$ to $10^{8} \mathrm{CFU} / \mathrm{ml}$ (Fig. 4A and C). Using the highest concentration, $>80 \%$ of both types

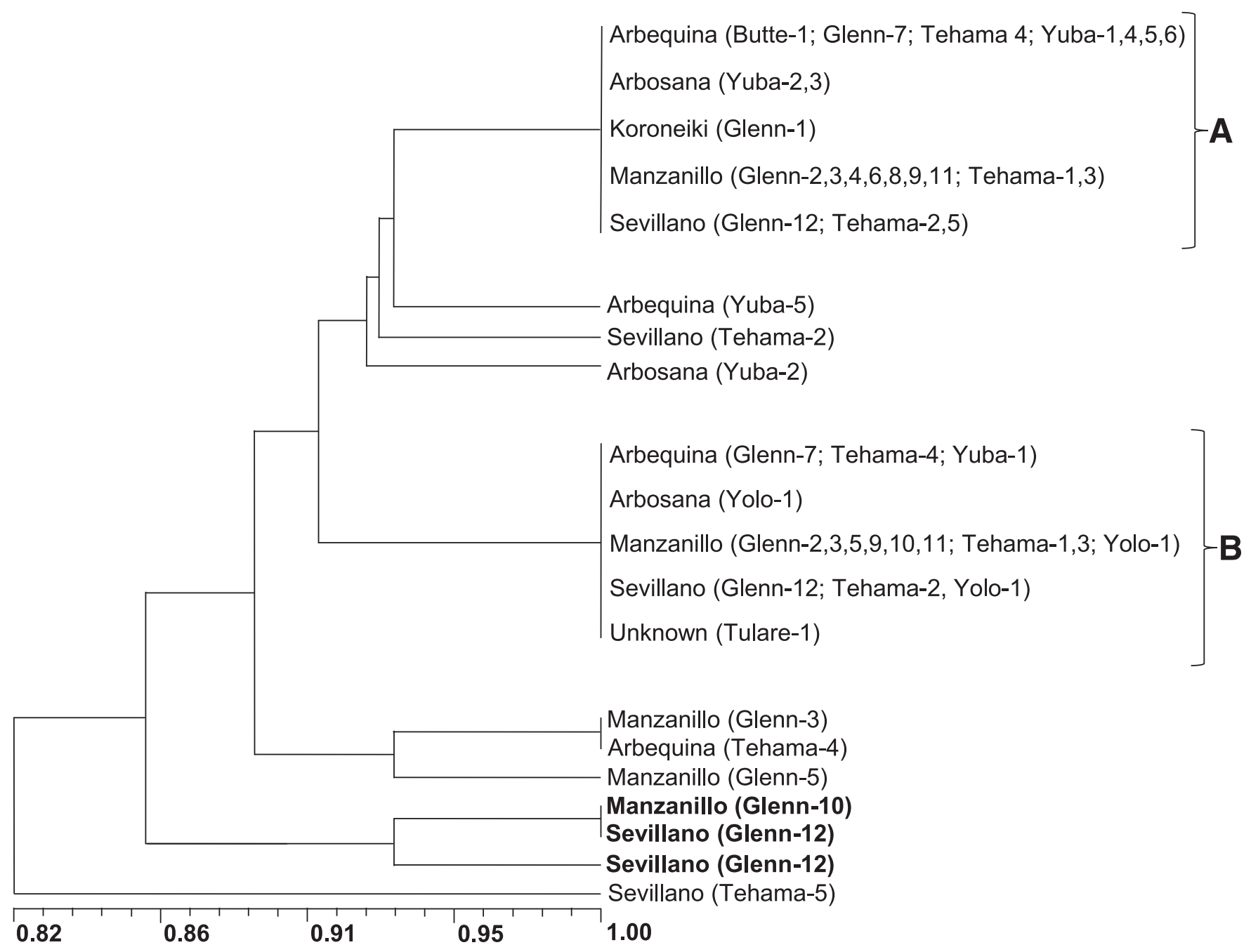

Dice similarity coefficient

Fig. 3. Unweighted pair-group method with arithmetic means (UPGMA) clustering of 152 Pseudomonas savastanoi pv. savastanoi strains from olive in California. Similarity is based on the combined electrophoresis banding patterns of REP, BOX, and ERIC primers using Dice's coefficient and UPGMA analysis. Two major groups of banding patterns A and B were identified. Olive cultivars and locations in bold indicate copper-resistant strains. 
of wounds developed knots. For leaf scars, there were significant differences in knot formation between the two strains $(P=0.0022)$, and there was no interaction $(P=0.1579)$ between strains and inoculum concentrations (Fig. 4A). Overall, the copper-sensitive strain was more virulent and caused significantly more disease (55\% knot formation) than the resistant strain (42.5\% knot formation). For lateral wounds, however, there was no significant difference in knot formation between the two strains $(P=0.1949)$, with the coppersensitive and -resistant strains causing 69.2 and $62.5 \%$ knot formation, respectively. There was also no interaction $(P=0.5653)$ between strains and inoculum concentrations (Fig. 4C).

In another study on the evaluation of inoculum concentrations for two copper-sensitive and two copper-resistant strains, droplet inoculations with defined amounts of cells were done in the greenhouse. The overall GLM model was significant for leaf scar and lateral wounds $(P<0.0002)$. For the two copper-sensitive and the two copper-resistant strains and for both types of wounds, incidence of knot formation increased significantly $(P<0.0001)$ for inoculum concentrations from $10^{3}$ to $10^{6} \mathrm{CFU} /$ wound (Fig. $4 \mathrm{~B}$ and D). The highest inoculum concentration of $10^{6} \mathrm{CFU} /$ wound resulted in $\geq 82 \%$ disease incidence for both types of wounds. Unlike in the spray inoculation studies, no significant $(P=0.0665)$ differences in disease incidence were observed among two copper-sensitive and two copper-resistant strains for both types of wounds at all inoculum concentrations, and there was no interaction $(P=0.4009)$ between strains and inoculum concentrations (Fig. 4B and D).

Similar results on the effect of inoculum concentration were also obtained when susceptibility of leaf scar and lateral wounds was compared on Arbequina and Manzanillo olive (Fig. 5A and B). The overall ANOVA models were highly significant $(P<0.0001)$ for both leaf scars and lateral wounds. Significant differences were observed between cultivars and inoculum concentrations for leaf scars $(P=0.0104$ and $P<0.0001$, respectively) and for lateral wounds ( $P=0.0155$ and $P<0.0001$, respectively). There was no interaction between cultivars and inoculum concentration for leaf scars $(P=0.9987)$ and lateral wounds $(P=0.6276)$. For leaf scars on Arbequina and Manzanillo, incidence of knot formation increased from 15.0 and 8.8 to 85 and $70 \%$, respectively (Fig. 5A); whereas, on
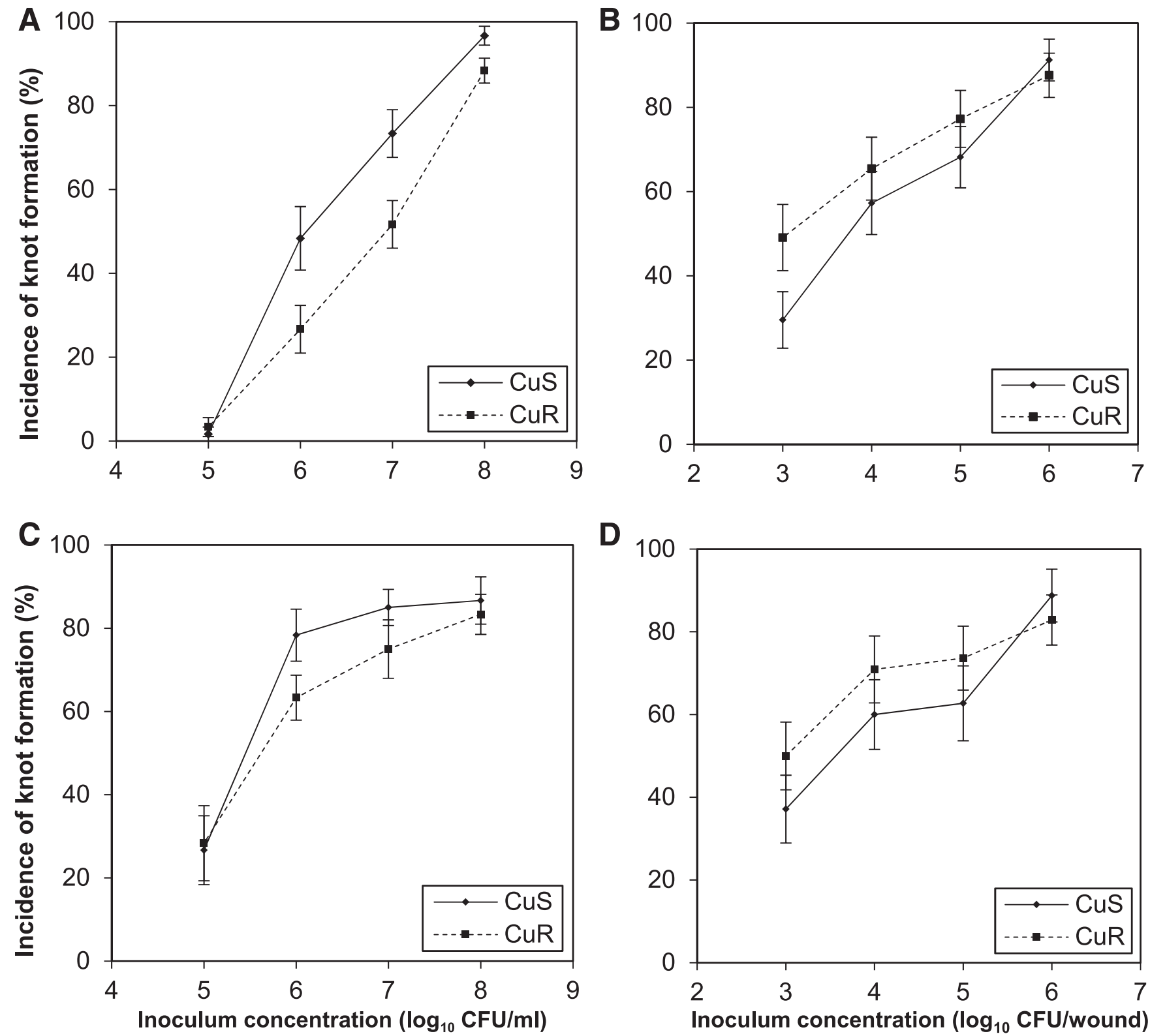

Fig. 4. Effect of inoculum concentration for copper-sensitive (CuS) and copper-resistant (CuR) Pseudomonas savastanoi pv. savastanoi strains on incidence of knot formation on $\mathbf{A}$ and $\mathbf{B}$, leaf scars and $\mathbf{C}$ and $\mathbf{D}$, lateral wounds of Arbequina olive using $\mathbf{A}$ and $\mathbf{C}$, spray inoculations in the field or $\mathbf{B}$ and $\mathbf{D}$, droplet inoculations in the greenhouse. Spray inoculations were done to runoff and, for droplet inoculations, $10 \mu \mathrm{l}$ of inoculum was applied to each wound. For spray inoculations, a single CuS (O26) or CuR (O113) strain was used. For droplet inoculations, CuS strains 014 and $\mathrm{O} 26$ and CuR strains 0113 and 0145 were used. Incidence is the average for all replications at each concentration. For the droplet inoculation, data were combined for CuS and CuR strains, respectively. Bars indicate the standard error. 
lateral wounds, incidence increased from 48.8 and 33.8 to 86.3 and $83.8 \%$, respectively (Fig. 5B), with inoculum concentrations increasing from $10^{5}$ to $10^{8} \mathrm{CFU} / \mathrm{ml}$. Overall, Arbequina had a significantly ( $P<0.0104$ for leaf scars, $P<0.0155$ for lateral wounds $)$ higher incidence of knot formation $(59.7 \%$ on leaf scars and $80.6 \%$ on lateral wounds) as compared with Manzanillo (47.4\% on leaf scars and $68.2 \%$ on lateral wounds).

Duration of susceptibility of lateral twig and leaf scar wounds to infection by $\boldsymbol{P}$. savastanoi pv. savastanoi. In field studies using Manzanillo olive, inoculation period after wounding had a significant effect $(P<0.0001)$ on incidence of knot formation of inoculated lateral and leaf scar wounds (Fig. 6). For the 0-day inoculations, incidence of knot formation on both types of wounds was $\geq 80 \%$ whereas, after 10 days, the incidence was reduced to $\leq 20 \%$. No significant difference in disease was observed among 10-, 20-, or 30-day-old leaf scar $(P=$ $0.3544)$ and lateral $(P=0.2352)$ wounds. The average air temperature for the first 10 days after wounding was $15^{\circ} \mathrm{C}$, average precipitation was $1.2 \mathrm{~mm}$, and average relative humidity was $40 \%$. These environmental conditions remained relatively constant for 20 or 30 days after wounding, with a slight decrease in air temperature and increase in relative humidity over the 30 -day period.
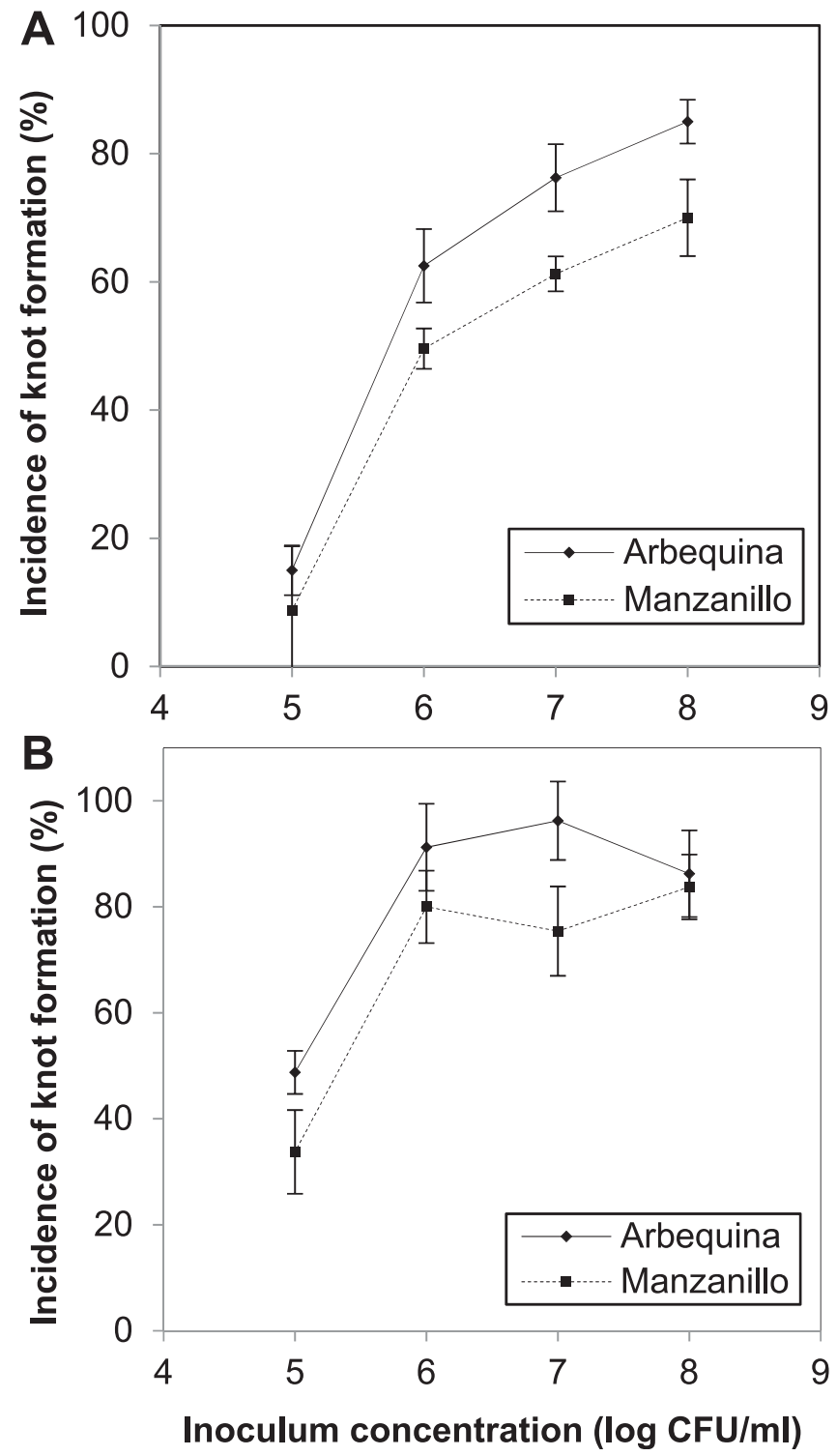

Fig. 5. Effect of inoculum concentration of Pseudomonas savastanoi pv. savastanoi strain 026 (copper sensitive) on incidence of knot formation on A, leaf scars and B, lateral wounds of Arbequina and Manzanillo olive. Data points are the means of two experiments. Bars indicate the standard error.

\section{Discussion}

Populations of $P$. savastanoi pv. savastanoi from olive in major California growing areas were found to be genetically diverse based on rep-PCR; however overall genetic variability was low, with strains sharing a minimum of $82 \%$ similarity. Thus, rep-PCR was able to identify considerable genetic diversity among our strains, whereas variability in $P$. savastanoi pv. savastanoi populations that was determined by others using multilocus sequencing was much more limited (Moretti et al. 2017, Tsuji et al. 2017). Our results are consistent with reports from growing areas in Mediterranean countries (Krid et al. 2009; Moretti et al. 2017; Scortichini et al. 2004; Sisto et al. 2007) and from nurseries and ornamental trees in Japan (Tsuji et al. 2017), where variability among pathogen strains was evaluated using a range of molecular methods. Still, in the latter studies, diversity was found mostly among geographic regions and not within locations. Thus, strains from the same orchards in Italy were all identical (Scortichini et al. 2004). Those from plantings in Tunisia were either identical or only two genotypes were identified that were, however, generally not present at other locations (Krid et al. 2009). In contrast in our study, either one of the two major genotypes that we identified was found in orchards in four or five counties in California, respectively, that are separated by distances of up to $300 \mathrm{~km}$. Additionally, there was no association of genotypes with a specific olive cultivar, and this was also observed in Mediterranean growing regions (Scortichini et al. 2004).

This difference in $P$. savastanoi pv. savastanoi genotype distribution between California and Mediterranean countries may be indicative of different methods of nursery stock distribution. Thus, whereas trees in Mediterranean countries are often propagated and then planted locally, nursery stock in California is provided by a limited number of propagation facilities that ship plants to growers throughout the state. Therefore, epiphytic populations of $P$. savastanoi pv. savastanoi on olive plants (Ercolani 1978) can be disseminated over long distances.

Interestingly, in our study, the three copper-resistant strains of $P$. savastanoi pv. savastanoi from two orchards in Glenn County did not group closely with any of the California genotypes of coppersensitive strains that we identified, including strains from the same locations. Copper resistance may have been introduced through replants from contaminated nursery stock or from other orchards or

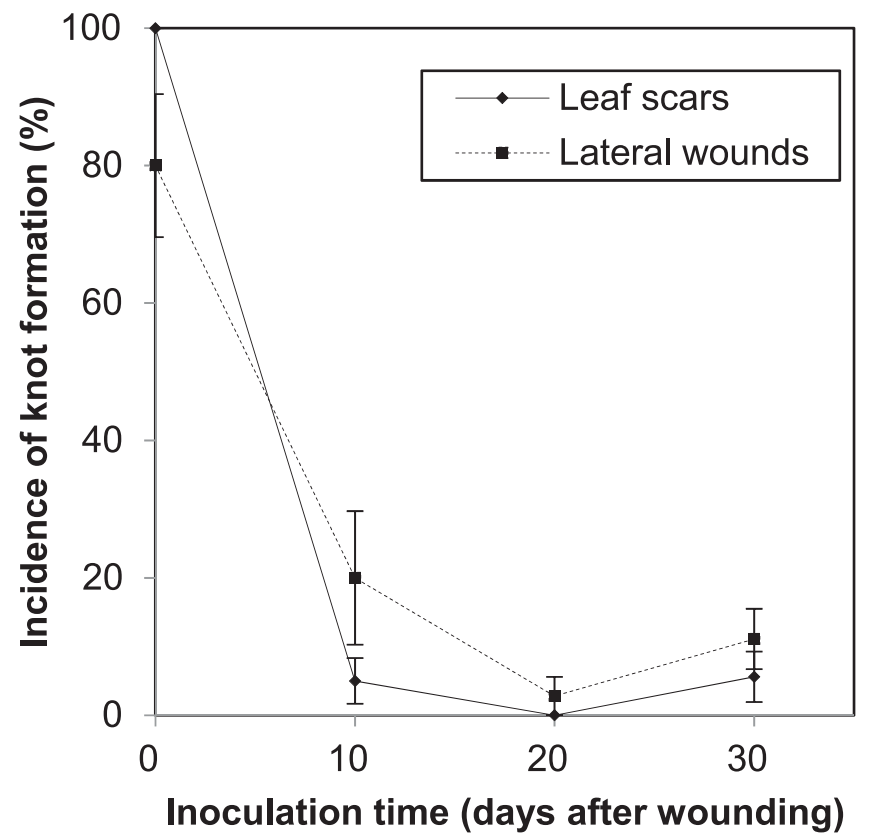

Fig. 6. Effect of wound healing duration of leaf scar and lateral wounds of Manzanillo olive on incidence of knot formation after inoculation with Pseudomonas savastanoi pv. savastanoi strain 026 (copper sensitive). Data points are the means of two experiments. Bars indicate the standard error. 
growing areas in the state that were not sampled. Because the pathogen is not specific to olive (Sisto et al. 2007), it also could have been introduced from ornamental hosts such as oleander. Furthermore, because the copper-resistant strains exhibited two different but related banding patterns, they may have been introduced independently. Additional sampling of olive knots in California as well as a worldwide comparison of strains may provide insight into the origin of copperresistant strains of $P$. savastanoi pv. savastanoi.

After soaking surface-disinfected olive knots in water, inoculum was exuded readily and at concentrations 2- to 3-log higher than the minimum amount needed to induce knot formation in spray inoculations. Similar results were obtained when using nonsurfacedisinfected knots (data not presented), suggesting that most of the viable bacterial cells were released from inside knots and that externally adhering bacteria did not contribute significantly to overall inoculum levels. Due to rapid inoculum availability during wetness events, our results emphasize the need to apply protective bactericide treatments before favorable environments (e.g., rainfall after any type of injury event, including mechanical harvesting, leaf drop, hail, or freeze) occur to prevent disease from developing (Nguyen et al. 2018).

Arbequina and Manzanillo represent the most widely planted oil and table olive cultivars, respectively, in California. In our studies, disease developed on lateral twig and leaf scar wounds inoculated with bacterial concentrations that were found to be naturally exuding from knots. Our findings are similar to those of Penyalver et al. (2006), who identified Arbequina as highly susceptible to olive knot. Manzanillo was also highly susceptible in our inoculation studies but significantly less susceptible than Arbequina. A high incidence of disease was obtained in inoculations of both types of wounds. Leaf removal in our assay, however, created an artificial wound, and natural leaf scars likely will be less susceptible to the inoculum concentrations evaluated because a protective abscission zone develops during annual leaf drop of olive (Hewitt 1938). In contrast, the lateral wounds we created were similar to those occurring during mechanical harvest and pruning. Thus, disease incidence resulting from these inoculations will likely reflect disease occurrence under commercial field conditions.

One of the copper-sensitive strains (i.e., O26) was found to be more virulent and induced significantly more disease than a copper-resistant strain, but only on leaf scars and when using the spray inoculation method. In additional studies using droplet inoculations, no significant differences in virulence were observed between two copper-sensitive and two copper-resistant strains and for both types of wounds. Because resistant strains of $P$. savastanoi pv. savastanoi were highly virulent overall, and because copper is the only highly effective and widely used bactericide in the management of olive knot, copper resistance is under positive selection pressure during times of the year when copper residues are present on trees (e.g., fall, winter, and spring). The resistant strains used in this study were detected after copper treatment failures in orchards were reported (Nguyen et al. 2018). Copper resistance may be a recent introduction into California. Based on the fitness of resistant strains to cause disease, there is a high risk of spread of copper resistance in California olive plantings if alternative management strategies are not developed.

In wound-healing studies, lateral and leaf scar wounds of Manzanillo olive were less susceptible to infection $\geq 10$ days after injury under our field conditions. Using Mission olive, Hewitt (1938) demonstrated that natural leaf scars were less susceptible to infection 7 days after leaf drop. Based on this and our studies, wound healing is important in relation to timing of orchard horticultural practices and disease management. The longer the period after pruning or mechanical harvest with no rainfall or wetness from irrigation, the less likely a successful infection will be established by the pathogen because of wound healing. Under California conditions, pruning should be done during lowrainfall periods such as mid- to late spring after leaf drop or early summer, but not after harvest in the fall or in the winter, when rains are likely to occur. Second, bactericide treatments should be applied during the most susceptible period of injuries (i.e., as soon as possible after they occur).

\section{Acknowledgments}

We thank E. Fichtner, D. Lightle, and W. Krueger (University of California Cooperative Extension, Tulare, Butte/Glenn, and Glenn Counties, respectively), as well as J. Post (Agricultural Advisors, Live Oak, CA) for assisting in collecting diseased olive samples; J. Preece for access to olive material in the United States Department of Agriculture National Clonal Germplasm Repository for olive; and $\mathrm{H}$. Azad for helpful discussions on bacterial plant pathology.

\section{Literature Cited}

Bioletti, F. T. 1898. The olive knot. Calif. Agric. Exp. Stn. Bull. 120.

Ercolani, G. L. 1978. Pseudomonas savastanoi and other bacteria colonizing the surface of olive leaves in the field. J. Gen. Microbiol. 109:245-257.

Hewitt, W. 1938. Leaf-scar infection in relation to the olive-knot disease. Hilgardia 12:39-71

Horne, T., Parker, B., and Daines, L. L. 1912. The method of spreading of the olive knot disease. Phytopathology 2:101-105.

King, E. O., Ward, M. K., and Raney, D. E. 1954. Two simple media for the demonstration of pyocyanin and fluorescein. J. Lab. Clin. Med. 44:301-307.

Krid, S., Rhouma, A., Quesada, J. M., Penyalver, R., and Gargouri, A. 2009. Delineation of Pseudomonas savastanoi pv. savastanoi strains isolated in Tunisia by random-amplified polymorphic DNA analysis. J. Appl. Microbiol. 106:886-894.

Moretti, C., Vinatzer, B. A., Onofri, A., Valentini, F., and Buonaurio, R. 2017 Genetic and phenotypic diversity of Mediterranean populations of the olive knot pathogen, Pseudomonas savastanoi pv. savastanoi. Plant Pathol. 66: 595-605.

Nguyen, K. A., Förster, H., and Adaskaveg, J. E. 2017. Quaternary ammonium compounds as new sanitizers for reducing the spread of the olive knot pathogen on orchard equipment. Plant Dis. 101:1188-1193.

Nguyen, K. A., Förster, H., and Adaskaveg, J. E. 2018. Efficacy of copper and new bactericides for managing olive knot in California. Plant Dis. 102:892-898.

Ogawa, J. M., and English, H. 1991. Olive knot. Pages 341-344 in: Diseases of Temperate Zone Tree Fruit and Nut Crops. University of California, Division of Agriculture and Natural Resources Publ. No. 3345, Oakland.

Penyalver, R., Garcia, A., Ferrer, A., Bertolini, E., and Lopez, M. M. 2000 Detection of Pseudomonas savastanoi pv. savastanoi in olive plants by enrichment and PCR. Appl. Environ. Microbiol. 66:2673-2677.

Penyalver, R., García, A., Ferrer, A., Bertolini, E., Quesada, J. M., Salcedo, C. I., Piquer, J., Pérez-Panadés, J., Carbonell, E. A., del Río, C., Caballero, J. M., and López, M. M. 2006. Factors affecting Pseudomonas savastanoi pv. savastanoi plant inoculations and their use for evaluation of olive cultivar susceptibility. Phytopathology 96:313-319.

Quesada, J. M., Penyalver, R., Pérez-Panadés, J., Salcedo, C. I., Carbonell, E. A., and López, M. M. 2010. Comparison of chemical treatments for reducing epiphytic Pseudomonas savastanoi pv. savastanoi populations and for improving subsequent control of olive knot disease. Crop Prot. 29:1413-1420.

Rademaker, J. L., and de Bruijn, F. J., 1997. Characterization and classification of microbes by rep-PCR genomic fingerprinting and computer assisted pattern analysis. Pages 151-171 in: DNA Markers: Protocols, Applications and Overviews. G. Caetano-Anollés and P. M. Gresshoff, eds. Wiley and Sons, New York.

Ramos, C., Matas, I. M., Bardaji, L., Aragón, I. M., and Murillo, J. 2012 Pseudomonas savastanoi pv. savastanoi: Some like it knot. Mol. Plant Pathol. 13:998-1009.

Rohlf, F. J. 2009. NTSYSpc: Numerical Taxonomy System, ver. 2.21q. Exeter Software, Setauket, NY.

Schroth, M. N., Osgood, J. W., and Miller, T. D. 1973. Quantitative assessment of the effect of the olive knot disease on olive yield and quality. Phytopathology 63:1064-1065.

Scortichini, M., Rossi, M. P., and Salerno, M. 2004. Relationship of genetic structure of Pseudomonas savastanoi pv. savastanoi populations from Italian olive trees and patterns of host genetic diversity. Plant Pathol. 53:491-497.

Sisto, A., Cipriani, M. G., Tegli, S., Cerboneschi, M., Stea, G., and Santilli, E. 2007. Genetic characterization by fluorescent AFLP of Pseudomonas savastanoi pv. savastanoi strains isolated from different host species. Plant Pathol. 56: 366-372.

Surico, G., and Lavermicocca, P. 1989. A semiselective medium for the isolation of Pseudomonas syringae pv. savastanoi. Phytopathology 79:185-190.

Tegli, S., Cerboneschi, M., Libelli, I. M., and Santilli, E. 2010. Development of a versatile tool for the simultaneous differential detection of Pseudomonas savastanoi pathovars by End Point and Real-Time PCR. BMC Microbiol. 10: 156

Tous, J., Romero, A., and Hermoso, J. F. 2010. New trends in olive orchard design for continuous mechanical harvesting. Adv. Hortic. Sci. 24:43-52.

Tsuji, M., Ohta, K., Tanaka, K., and Takikawa, Y. 2017. Comparison among Japanese isolates of Pseudomonas savastanoi pv. savastanoi, causal agent of olive knot disease. J. Gen. Plant Pathol. 83:152-161.

Vossen, P. 2007. Olive oil: History, production, and characteristics of the world's classic oils. HortScience 42:1093-1100.

Wilson, E. E. 1935. The olive knot disease: Its inception, development and control. Hilgardia 9:231-264.

Young, J. M. 2004. Olive knot and its pathogens. Australas. Plant Pathol. 33 33-39. 